\title{
A Critical Time for Virtual Critical Literacy
}

\author{
Dr. Rebekah Taylor and Dr. Kathryn Sharp
}

The COVID-19 pandemic has changed almost every aspect that we as Americans considered normal including handwashing, shopping supply lists, socializing, and definitely early childhood teaching. With most American schools and universities physically closed, many teachers and professors have resorted to online teaching as their mean of sharing information and knowledge. For many, this has been a trial and error situation and many have had to figure it out on their own. During this time of unrest and uncertainty, perhaps early childhood teachers should utilize critical literacy and take advantage of a time to talk about morals, ethics, sympathy, empathy and other emotions rather than skills. Although critical literacy is always a strong teaching practice, it seems that there is a place for critical literacy in early childhood education, maybe now more than ever before.

Critical literacy can be defined as "the ability to read texts in an active, reflective manner in order to better understand power, inequality, and injustice in human relationships" (Coffey 2008, para. 1). Through the COVID 19 pandemic, power has been demonstrated through our leaders who have made shelter in place decisions and some who have demonstrated power by not making shelter in place decisions. Power has been demonstrated by the choosing of which businesses are deemed essential and get to remain open. Power has also been demonstrated with economic decisions such as stimulus checks intended to help subside the economic loss some experience by their loss of income.

Inequality may be displayed as well as doctors face ethical challenges of who would be eligible for a ventilator if the need to triage came to fruition (Truog, Mitchell, \& Daly, 2020). The director of the Center for Bioethics at Harvard Medical School, says American doctors may face new ethical challenges in trying to triage limited ventilators for COVID -19 patients. Many of our children are acclimated to inclusion of children with special needs. How would we explain to them that their state denied a ventilator to one of their classmates with special needs (Cha \& McGinley, 2020)?

We have witnessed injustice and inequality of systemic racism in the amount of deaths in the African-American communities. This can clearly be seen in Louisiana, where blacks account for 70 percent of the deaths but 33 percent of the population (Bouie, 2020).There are similar statistics existing for Chicago and Detroit where most low-paying service jobs employ African Americans. They therefore are more likely not to have an automobile and rely on public transportation and have jobs that put them in the public sector and in harm's way of COVID-19 (Bouie, 2020).

Shielding and protecting young children in order for them to remain innocent and simple (Dresang, 2003) is a concept shared by many and can be traced back to Jean-Jacques Rosseau's (2013) feelings as he wrote about how children should be protected and shielded in Emile. However, Meller, Richardson, \& Hatch (2009) stated that young children can and should participate in critical literacy aspects of discussion and writing. These should follow a teacher read-aloud of a high quality book that emphasizes social concerns. Furthermore, Chafel, Flint, Hammel, and Pomeroy (2007) stated that young children are capable of answering and discussing teacher questions about the text such as, "What do you think that author wants us to think about their text?" exemplifying teaching author's purpose as part of critical literacy. This type of question requires more than a "yes/no" response and enables students to learn to develop thinking skills and provide a voice in the story rather than just providing one correct answer (Vasquez, 2004). While young children are quarantined in their homes, many witnessing and experiencing stress from income loss, sickness, confusion, and in some cases death of family members or people they know, this time should be used to explain what is happening so they can understand and be a part of a bigger solution now and in the future rather than being sheltered from this historical pandemic; critical literacy is the bridge.

As an early childhood teacher, I can attest to the stress that the pandemic has caused educators. Like many teachers, I have created online lessons and read alouds. I have tried to maintain contact with my students with pictures, videos, and Zoom. My first Zoom meeting with my students included a low participation percentage even though the parents and guardians had indicated they had internet capability at their homes. Although the excitement of seeing each other was heartwarming, it was a colossal failure as any type of critical discussion. Because we were not in the classroom, any rule for discussion or social etiquette was nonexistent. Children were talking at the same time with one consistently asking, "Do you remember me?" to everyone on the screen. I found that I had to mute some children in order to hear only one. Seeing the faces and hearing the voices of the ones that did join brought great joy, however, I wanted to really know what they were thinking and feeling. 
Did they have fears? Were they worried or anxious? Were they hungry? It is these feelings and thoughts that will be history one day, and it is these feelings and thoughts that could provide answers for the future. They need to be expressed, be acknowledged, and be recorded. In attempt to promote the importance of virtual critical literacy, I have put my money where my mouth is so to speak and have chosen books that can dig a little deeper and ask students why the author chose a particular action and how it can relate to the current situation. . The pandemic disrupts common place situations or thinking, lends itself to multiple perspectives, demonstrates socio political issues, and provides an opportunity to take a stance against an injustice or in favor of something right. These are the four components of critical literacy as defined by Lewison, Flint, and Van Sluys (2002). McLaughlin and DeVoogd (2004) stated that there is no one method to best teach critical literacy. Instead, best methods are determined by the text and the students' abilities that allow them to engage in a dialogue or writing that questions the text. The text should also reflect the current social and political contexts. When critical analysis of text is performed, critical literacy has the potential to promote social justice by providing opportunities to evaluate and question text. Therefore, writing was emphasized since the discussion was not fruitful.

Examples of books that are commonly chosen and are well suited for critical literacy in early childhood include: The Rainbow Fish, The Other Side, The Lady in the Box, and No David! These books introduce manipulation, race, homelessness, and power. Students can then evaluate truth and bias in text, cast judgment, and ultimately take a stance on issues that promote inequality. Although, the texts for critical literacy continue to develop as the need is recognized, at the time of this writing, this does not include books about pandemics. However, following Mclaughlin and DeVoogd's (2004) suggestion that there is not one best way to teach critical literacy and books should be determined by the abilities for students to engage, books were chosen where a character or an event could be questioned and possibly related to the current pandemic happenings and events.

The first book chosen was Thundercake (Polocco, 1990). In this book the character is afraid of storms and her grandmother lures her out from her hiding place under the bed with a recipe and plan to make Thundercake. In my video to the students I asked them about the little girl hiding under the bed and her actions. I then went on to ask them to write about a fear they currently have about the covide-19 pandemic. One student wrote that hiding under the bed did not help solve the problem. Another student expressed her fears in her writing. She wrote, "I am afraid

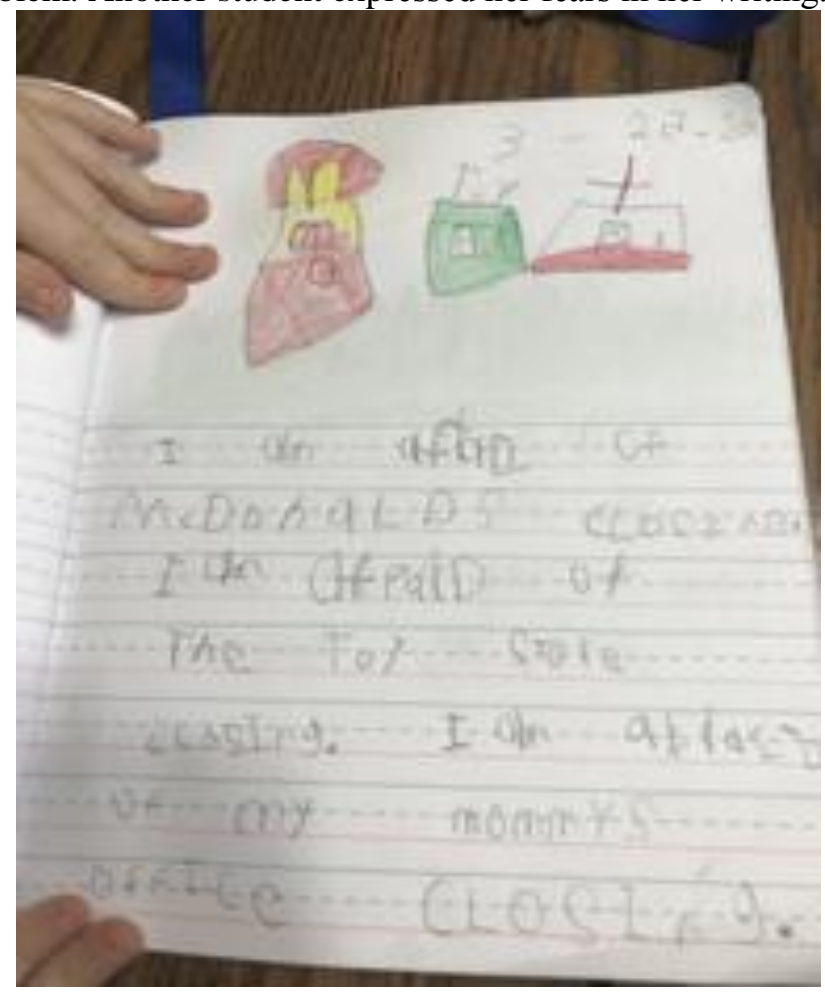

of McDonald's closing. I am afraid of the toy store closing. I am afraid of my mommy's office closing." Her fear of "Mommy's office closing" reflects the economic issues which faced many Americans during this trying time. Her words express not only the concerns reflective of a five year old by writing of toys and McDonald's, but also the fears of adults in danger of losing their jobs. She was not only able to express her thoughts and fears in writing but also engage in a dialogue with her mother about her job when her mother discovered she had this fear.

After reading the writings about existing fears, I wanted to provide some comfort by assuring students that there are brave people trying to help others medically and financially. It is a time when we all must be courageous as we brave unchartered waters. For bravery, the book Max the Brave (Vere, 2014) was chosen. I chose this book because Max wants to be brave and catch a mouse. However, he has no idea what a mouse is. 
This seemed fitting as we do not know exactly what COVID-19 looks like since it has a multitude of symptoms that affect people differently and we have not seen this illness before. I asked children to think about the character of Max and if the story would have been different if Max were a girl. Could she still be brave? (In order to help ease their fears, I also asked them to write about brave people in order to help them recognize that men and women have jobs that battle COVID-19 daily. One student wrote about her own family:

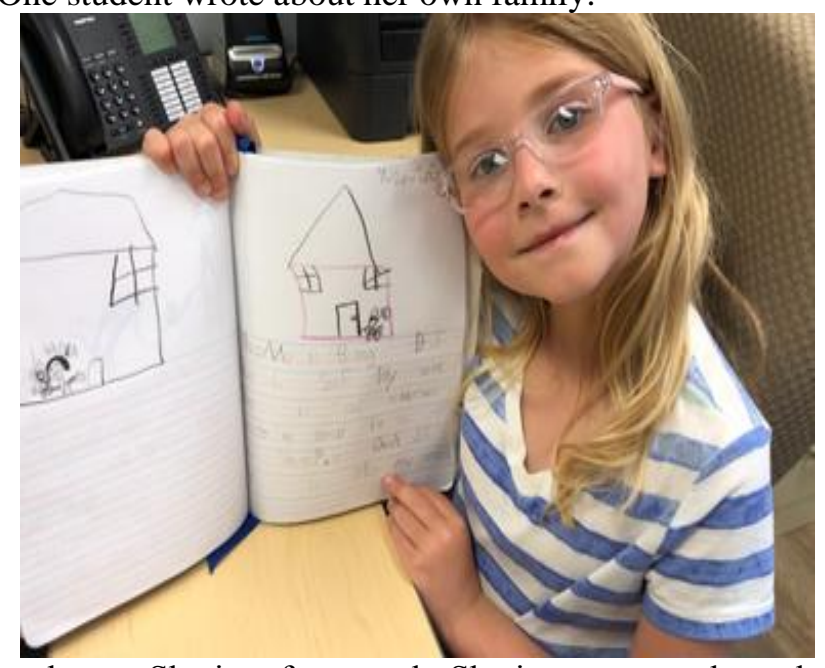

"Girls are brave too. Mom is being brave. She is safe at work. She is a nurse and my dad he is a sheriff." Writing about her parents being brave, not only gave her comfort, but also made her proud. Replacing the male character of Max with a girl character, represents disrupts the common place thinking component of critical literacy.

Recognizing the students' fears and thoughts about bravery, I found myself confused by the number of nonessential people ignoring the Center for Disease Control (CDC) guidelines about social distancing and staying home. Because of this, the next book chosen was The Carrot Seed (Krauss, 1945). In this book, the boy planted a carrot seed and his parents tell him he should not water it or pull the weeds around it because it "won't come up." He ignored his parents and continued to water, weed, and tend to the carrot seed. The end of the book finds the boy harvesting a huge carrot. I asked the students if they thought it was ok that he continued to tend to the seed even though his parents told him not to. Is it ok to not do what we're told sometimes and why did they think this?

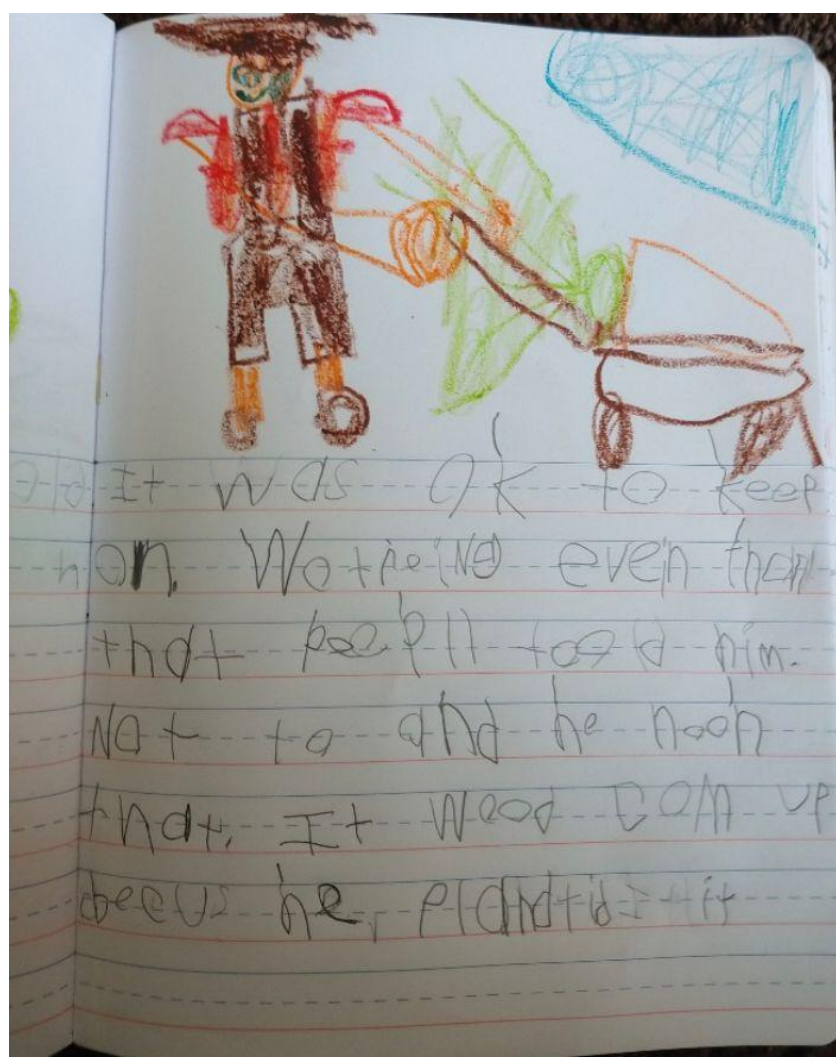

This student wrote, "It was ok for him to keep on watering it even though people told him not to, and he knew that it would come up because he planted it." 
Another book chosen was The Sunflower House (Bunting, 1999). In this book, a child's parent helps him plant sunflowers in a circle rather than a straight line. They grew tall and formed a "house" for play and campouts. As the sunflowers start to fade, he becomes sad. However, he harvested the seeds and made plans for the next growing season to plant it again. I asked the students to think about something that might be making them sad, but to "take a stance "and think of a way that could make it better.

One student wrote that "No body is coming to my birthday and I am sad. But I am going to have a good birthday party." His picture shows him with his parents having a birthday party. He recognized his feelings of sadness, but "took a stance" and decided he will still have a birthday with his parents.

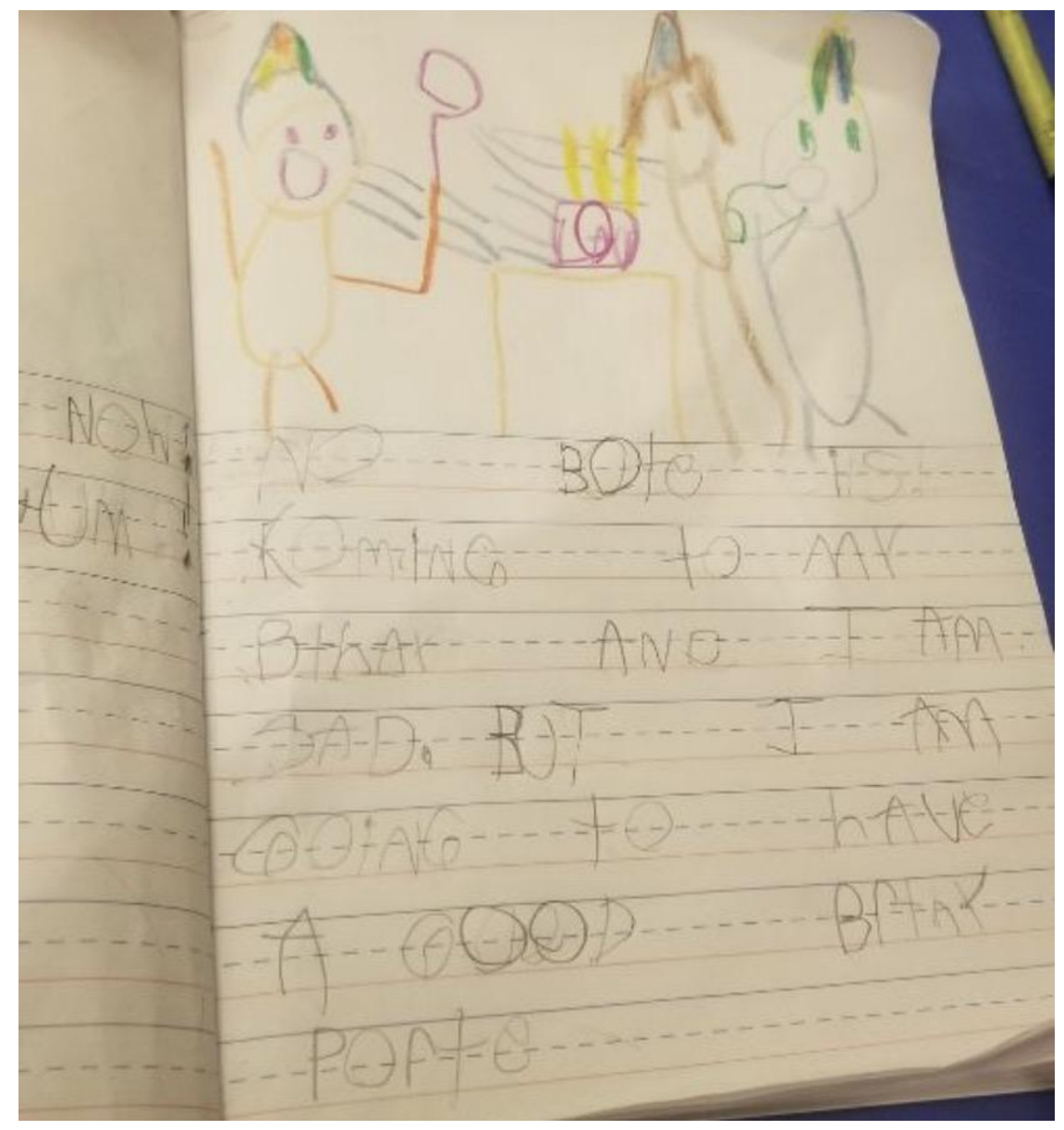

Tops and Bottoms has always been a favorite book of mine and students too. The sly hare in the story tricks the bear three times when growing vegetables, and left bear with nothing edible and saved the good parts for himself. I asked the students to think about rabbit and bear's characters and situations and to put themselves into one of them and write about if they thought the character made the right decision or not. This gave students an early opportunity to explore multiple perspective. 


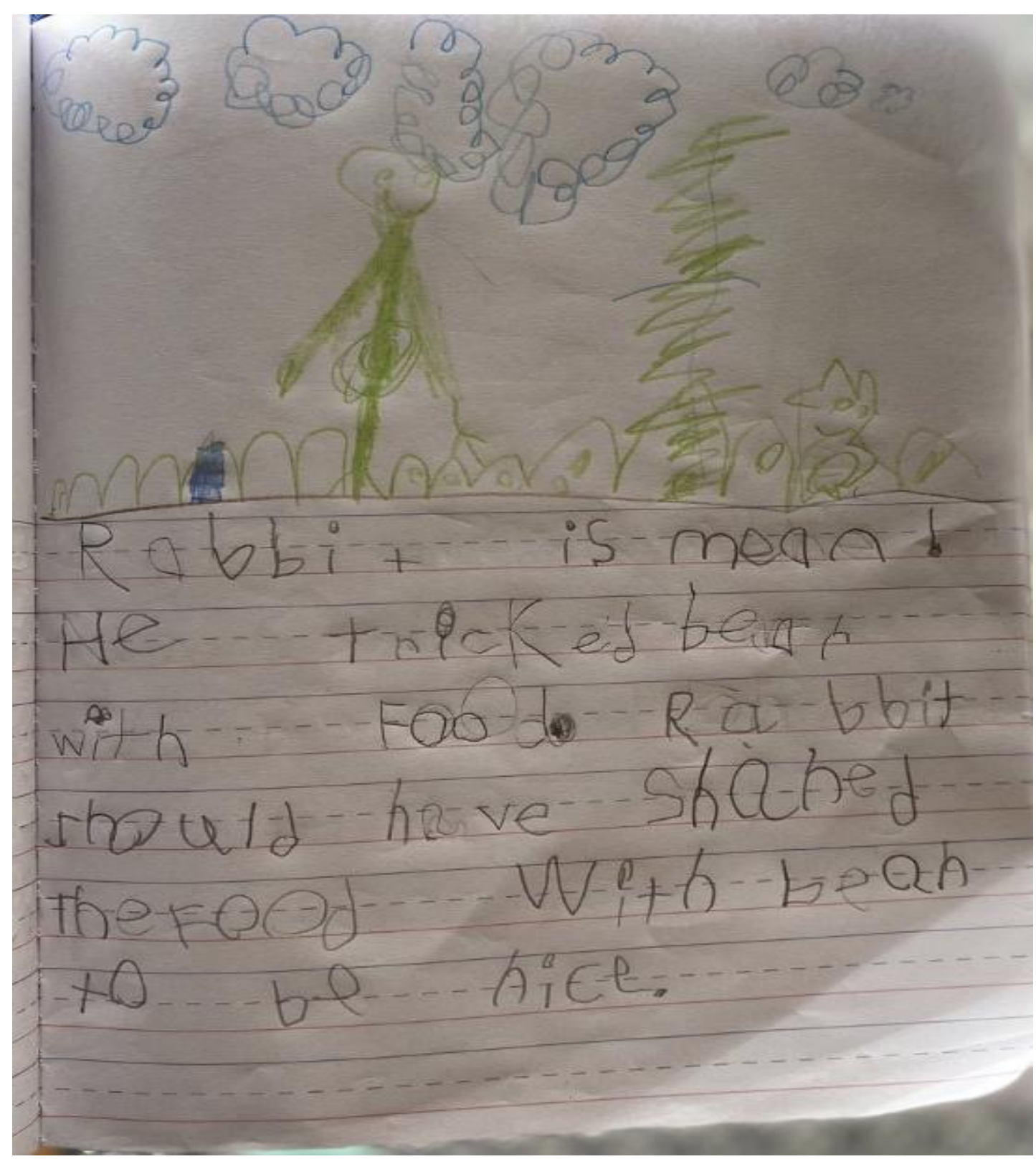

One student wrote that, "Rabbit was mean! He tricked bear with food! Rabbit should have shared the food with bear to be nice." He picked the rabbit's view and although the author stated that hare and his family had no food, this student did not think rabbit should have taken advantage of bear.

Tops and Bottoms, The Sunflower House, and The Carrot Seed all followed the unit of study of plants. These books therefore were easily incorporated into the unit which met state standards demonstrating how books that have a good text can be used for critical literacy. These books also demonstrate that analysis can be performed with young children. In fact it is recommend as one of the procedures that teach reading skills to young children in The Four Resource Models (Freebody \& Luke, 1999; Luke \& Freebody, 1990). Freebody \& Luke's (1999) Four Resource Models include: code breaking, text participation, text use, and text analysis. However, the last piece of text analysis, which embodies critical literacy, is often omitted. This omission places emphasis on the other three components of the model and disregards the far reaching and flexible practices of sociocultural experiences present in society and educational institutions (Freebody \& Luke, 1999). Continuing to have students write and analyze with virtual critical literacy keeps them abreast and involved in the socio cultural and socio political happenings in the world.

Critical literacy is always meaningful, but even more so now during this time of virtual learning. It is unclear at this time when a second wave of the COVID-19 will come, but there is a second wave predicted and expected. Predictions vary, but some universities have already announced decisions to continue with online classes in the fall. It would not be surprising for some school districts to follow their lead. Recognition of children's feelings and emotions and analysis through text needs to continue virtually if this is the case. Our children need to not be sheltered at this time, but aware in order to be part of a future solution. 


\section{References}

Bouie, (2020, April 14). Why Coronavirus Is Killing African-Americans More Than Others

Higher rates of infection and death among minorities demonstrate the racial character of inequality in America. The New York Times.https://www.nytimes.com/2020/04/14/opinion/sunday/coronavirus-racism-africanamericans.html

Cha, A. and McGinley, L. (2020, April 7). Who gets a shot at life if hospitals run short ofventilators?States, hospitals scramble to set guidelines that could prioritize pregnant women, health-care workers - and even some politicians. The Washington Post. https://www.washingtonpost.com/health/2020/04/07/ventilatorsrationing-coronavirus-hospitals/

Chafel, J. A., Flint, A. S., Hammel, J., \& Pomeroy, K. H. (2007). Young children, social issues, and critical literacy stories of teachers and researchers. Young Children, 62(1), 73.

Coffey, H. (2008). Critical literacy. Retrieved February 18, 2017, from http://www.learnnc.org/lp/pages/4437?ref=search

Dresang, E. (2003). Controversial books and contemporary children. Journal of Children's Literature. 29(1), $20-31$.

Freebody, P., \& Luke, A. (1999). Further notes on the four resources model. Reading Online, Retrieved February 18, 2017 from: https://pdfs.semanticscholar.org/a916/0ce3d5e75744de3d0ddacfaf6861fe928b9e.pdf

Lewison, M., Flint, A. S., \& Van Sluys, K. (2002). Taking on critical literacy: The journey of newcomers and novices. Language Arts. 79(5), 382-392.

McLaughlin, M., \&DeVoogd, G. L. (2004). Critical literacy: Enhancing students'comprehension of text. New York: Scholastic.

Meller, W. B., Richardson, D., \& Hatch, J. A. (2009). Using read-alouds with critical literacyliterature in K-3 classrooms. Young Children. 64(6), 76-78.

National Association of the Education of Young Children (2009). Developmentally appropriate practice in early childhood programs serving children from birth through age 8[Policy Statement]. Retrieved October 20, 2018, from https://www.naeyc.org/resources/position-statements/equity-draft

Truog, R., Mitchell, C. \&Daley, G. (2020). The toughest triage - Allocating ventilators in a Pandemic. The New England Journal of Medicine. Doi:DOI: 10.1056/nejmp2005689

Vasquez, V. M. (2004). Negotiating critical literacies with young children. New York, NY: Routledge. 